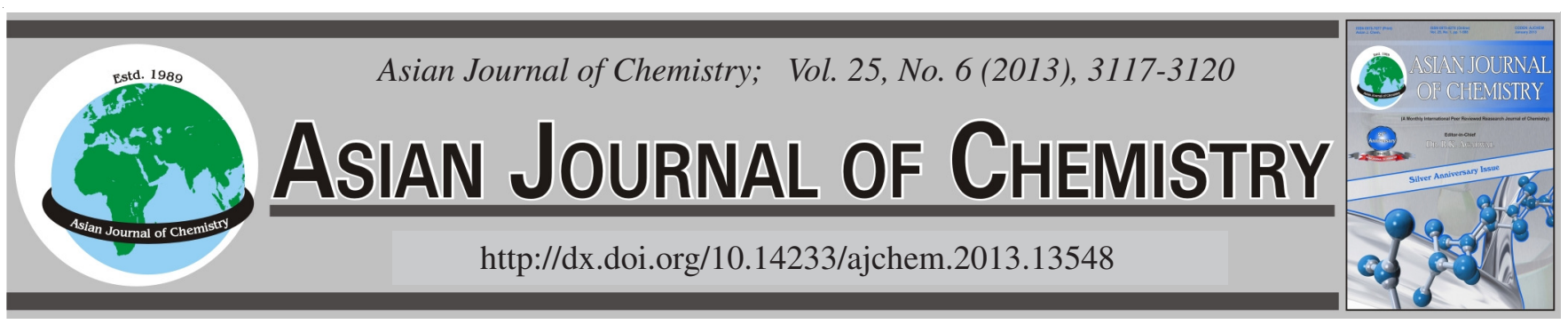

\title{
Corrosion Inhibition Mechanism of Pyridine on Iron and Its Alloys Using DFT
}

\author{
V.H. HOANG ${ }^{1, *}$, T.D. NGUYEN ${ }^{1}$ and N.H. NGUYEN ${ }^{2}$
}

${ }^{1}$ Faculty of Chemistry, Hanoi National University of Education, Hanoi, Vietnam

${ }^{2}$ Centre for Computational Science, Hanoi National University of Education, Hanoi, Vietnam

*Corresponding author: Tel: +84 43 8330842, E-mail: hunghv@hnue.edu.vn; hung.hoang@s2002.tu-chemnitz.de

DFT method has been used to interpret the corrosion inhibition mechanism of pyridine on iron surfaces. The analysis of partial density of states and Fukui function revealed that pyridine molecules are adsorbed on iron surfaces to form a protective layer and increase ionization energy of surface iron atoms. The electron shift from surface iron atoms to pyridine molecules increases interaction between $\mathrm{H}^{+}$and $\mathrm{N}$ atom in pyridine molecules, but reduces the attack of $\mathrm{H}^{+}$species to iron surface.

Key Words: Pyridine, DFT, Corrosion inhibition.

\section{INTRODUCTION}

Organic substances containing heteroatoms such as nitrogen and oxygen have been used intensively as corrosion inhibitors of metals in acidic media ${ }^{1-4}$. These substances are adsorbed on the metallic surfaces and prevent their degradation ${ }^{5}$. Many experimental studies have been carried out to reveal corrosion efficiency of a series of chemical compounds. Theoretical studies based on quantum chemical calculations can be helpful in selecting and designing possible corrosion inhibitor substances because these calculations can provide qualitative, semi-qualitative useful information to better understanding the undergoing inhibition processes and predict a number of molecular parameters directly related to the corrosion inhibitor property of any chemical compound ${ }^{6,7}$. Therefore, nitrogen-containing compounds, especially, pyridine and its derivatives, have been studied theoretically as corrosion inhibitors on surface of metals using DFT method in recent years $^{8-11}$. Nevertheless, all these calculations used cluster model for metal surfaces and the properties of cluster systems are similar to those of nano systems, but far different from those of real systems. As a result, the real systems could not be characterized by obtained results.

In general, working with model of the real system, a periodic system, faces with many difficulties. (i) The periodic system normally has a large size, contains a lot of atoms and thus calculations are time-consuming and need to use algorithms with periodic boundary conditions. (ii) Effect of solvent on periodic system must be taken into account, though most of the previous calculations were carried out in the gaseous phase and effect of solvent was not mentioned. (iii) Calculations for real system, an impure metal surface, are very complicated.

In order to obtain results in good agreement with real systems, in this work, all three above problems have been solved. A model of $\mathrm{Fe}(001)-3 \times 3 \times 2$ with space of $20 \AA$, with the simulation box (or super-cell) size of $8.6 \times 8.6 \times 24.3 \AA$ and with periodic boundary conditions was employed. Each super-cell consists of 36 atoms with four nice-atom layers (Fig. 1). For impure system, a system containing $\mathrm{C}$ or $\mathrm{O}$ atom, impure atom was placed in octahedral cavity, denoted as $\mathrm{X}$ in Fig. 1 and closest to the pyridine molecule adsorbed on $\mathrm{Fe}(001)$ surface.

\section{EXPERIMENTAL}

Computational methods: The DFT method with gradientcorrected (GGA) functional of Perdew-Wang generalizedgradient approximation (PW91) ${ }^{13}$ and the Gaussian doublezeta basis set has been used in all calculations. Because the selected system is big and contains Fe atoms, electron-rich atoms, it leads to chemical calculations at ab initio level which are time-consuming and require how to balance between the accuracy and speed of calculations.

To reduce computational efforts, here, only valance electrons of iron were considered and the atom core was treated by means of the pseudopotential method, the norm-conserving pseudopotentials ${ }^{14}$. The Brillouin zone sampling has been applied by the Monkhorst-Pack ${ }^{15} \mathrm{k}$-points of $2 \times 2 \times 1$, that is effective enough for this big system. 
TABLE-1

SOME CALCULATION RESULTS COMPARED TO EXPERIMENTAL DATA. BOND DISTANCE $\mathrm{r}(\AA)$, FIRST FOUR HIGHEST FREQUENCIES $v\left(\mathrm{~cm}^{-1}\right)$ AND LATTICE PARAMETER $\mathrm{a}_{0}(\AA)$

\begin{tabular}{|c|c|c|c|c|c|c|c|}
\hline & & $\mathrm{r}(\mathrm{N}-\mathrm{C} 1)$ & $\mathrm{r}(\mathrm{C} 1-\mathrm{C} 2)$ & $v$ & $v$ & $v$ & $v$ \\
\hline \multirow[t]{2}{*}{ Pyridine } & Cal. results & 1.370 & 1.424 & 3089.7 & 3081.0 & 3068.0 & 3048.3 \\
\hline & Exp. data ${ }^{16,17}$ & 1.340 & 1.390 & 3094.2 & 3086.9 & 3072.8 & 3042.4 \\
\hline \multicolumn{8}{|c|}{$\mathrm{a}_{0}$} \\
\hline \multirow[t]{2}{*}{ Fe crystal } & Cal. results & 2.9976 & \multirow{2}{*}{\multicolumn{5}{|c|}{ Calculated with Monkhorst-Pack k-points of $8 \times 8 \times 8$}} \\
\hline & Exp. data ${ }^{18}$ & 2.8664 & & & & & \\
\hline
\end{tabular}

TABLE-2

CHARGE AND FUKUI FUNCTION FOR RADICAL ATTACK (MULLIKEN)

\begin{tabular}{lccccccc}
\hline Atom & $\mathrm{N}$ & $\mathrm{C} 1$ & $\mathrm{C} 2$ & $\mathrm{C} 3$ & $\mathrm{H} 1$ & $\mathrm{H} 2$ & $\mathrm{H}$ \\
\hline Charge & -0.370 & 0.006 & -0.119 & -0.098 & 0.113 & 0.123 & 0.118 \\
\hline Fukui function & 0.134 & 0.082 & 0.071 & 0.073 & 0.098 & 0.098 & 0.096 \\
\hline
\end{tabular}

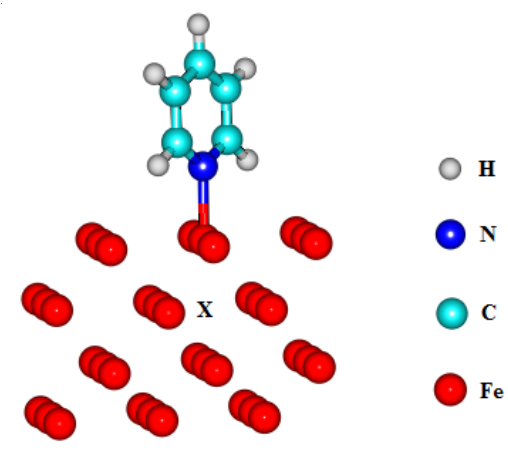

Fig. 1. Model of $\mathrm{Fe}(001)-3 \times 3 \times 2$ and pyridine (or one super-cell) Salvation effects of water have been taken into account by the conductor-like Screening Model (COSMO) $)^{12}$

To confirm the selected computational methods are good enough, some additional calculations have been done (Table-1). The calculation results are in good agreement with the experimental data and therefore reveal that the selected parameters as well as computational methods are well accepted to be used for the system.

\section{RESULTS AND DISCUSSION}

Electronic structures of pyridine and $\mathrm{Fe}(001)$ : Understanding the properties and electron structures of pyridine and $\mathrm{Fe}(001)$ helps us to analyze and investigate mechanism of corrosion inhibition easily and clearly. All our calculations were carried out with the presence of water molecules as solvent molecules.

Pyridine: The Fukui function ${ }^{19,20}$ is defined as the derivative of the electron density, $\rho(r)$, with respect to the total number of electrons of the system, $\mathrm{N}$, under a constant external potential, $v(r)$.

$$
f(r)=\left(\frac{\partial \rho(r)}{\partial N}\right)_{v(r)}
$$

It has been used with great success in many applications to chemical reactivity and site selectivity studies ${ }^{27,28}$. Table-2 shows obviously that value of Fukui function of $\mathrm{N}$ atom in pyridine molecule is much greater than that of other atoms. This means that $\mathrm{N}$ atom in pyridine molecule has the highest reactivity. The results are in good agreement with other studies ${ }^{18}$. When pyridine molecules are adsorbed on iron surface, orientation of N...Fe is more favour.
The partial density of states, which is the components of the total density of states and shows the energy content of individual orbitals, is defined as:

$$
\mathrm{g}_{\mathrm{j}}(\varepsilon, \mathbf{r})=\sum_{\mathrm{i}}\left|\left\langle\chi_{\mathrm{j}} \mid \psi_{\mathrm{i}}(\mathbf{r})\right\rangle\right|^{2} \delta\left(\varepsilon_{\mathrm{i}}-\varepsilon\right)
$$

where, $\varepsilon_{\mathrm{i}}$ is the Kohn-Sham eigen value corresponding to the Kohn-Sham orbital $\psi_{\mathrm{i}}(\mathrm{r})$ and $\delta\left(\varepsilon_{\mathrm{i}}-\varepsilon\right)$ is delta Dirac function, $\chi_{\mathrm{j}}$ is the angular momentum component at each orbital such as $s, p$ or $d$. Results of partial density of state analysis of $p$ states for pyridine are illustrated in Fig. 2.

Fig. 2 shows that partial density of states of $\mathrm{N}$ atom reaches maximum value at Fermi level, the highest occupied molecular orbital (HOMO). This means that electrons having highest energy have the highest probability to be at $\mathrm{N}$ atom. In addition, density state of un-occupied $p$ (located over Fermi level) of $\mathrm{N}$ atom is greater than that of $\mathrm{C}$ atoms leading to the highest reactivity of $\mathrm{N}$ atom in pyridine.

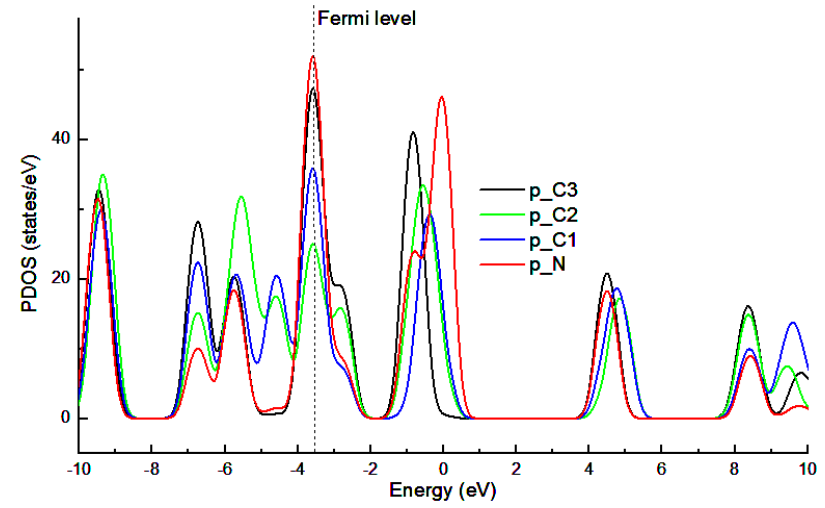

Fig. 2. Partial density of states of $p$ states for $\mathrm{N}$ and $\mathrm{C}$ atoms in pyridine

Fig. 3 shows the energy band of Fe bulk (a) Fe(001) b.

$\mathbf{F e}(001)$ thin film: Fig. 4 confirms that for iron, a group $d$ metal, state of $d$-orbitals is more important than that of $\mathrm{p}$ and $s$ orbitals. At region adjacent and under Fermi level, electrons are mainly filled in $d$ state band, whilst at high energy level $p$ state forms unoccupied energy band over Fermi level.

Mechanism of corrosion inhibition of metal and interaction between pyridine and iron on surface: Literature reveals that the corrosion inhibitory of pyridine is due to strong interaction of pyridine molecules with surface iron atoms 
TABLE-3

CHARGES OF ATOMS IN PYRIDINE MOLECULE AFTER ABSORPTION,

DISTANCE $(d)$, OF N $\cdots \mathrm{Fe})$, ABSORPTION ENERGY, $\mathrm{E}_{\text {ads, }}(\mathrm{kJ} / \mathrm{mol})$

\begin{tabular}{|c|c|c|c|c|c|c|c|c|c|}
\hline & $\mathrm{N}$ & $\mathrm{C} 1$ & $\mathrm{C} 2$ & C3 & $\mathrm{Fe}$ & $\mathrm{C}(\mathrm{Fe})$ & $\mathrm{O}(\mathrm{Fe})$ & $\mathrm{d} / \AA$ & $\mathrm{E}_{\mathrm{ads}} / \mathrm{kJ} \mathrm{mol}^{-1}$ \\
\hline $\mathrm{Py}$ & -0.370 & 0.006 & -0.119 & -0.098 & & \multirow{4}{*}{0.115} & \multirow[b]{4}{*}{-0.520} & & \\
\hline $\mathrm{Py}-\mathrm{Fe}$ & -0.421 & -0.063 & -0.195 & -0.183 & 0.154 & & & 2.054 & -198.663 \\
\hline $\mathrm{Py}-\mathrm{Fe}(\mathrm{C})$ & -0.439 & -0.040 & -0.194 & -0.184 & 0.150 & & & 2.014 & -217.470 \\
\hline $\mathrm{Py}-\mathrm{Fe}(\mathrm{O})$ & -0.430 & -0.038 & -0.192 & -0.184 & 0.274 & & & 1.993 & -209.984 \\
\hline
\end{tabular}

Energy $(\mathrm{Ha})$

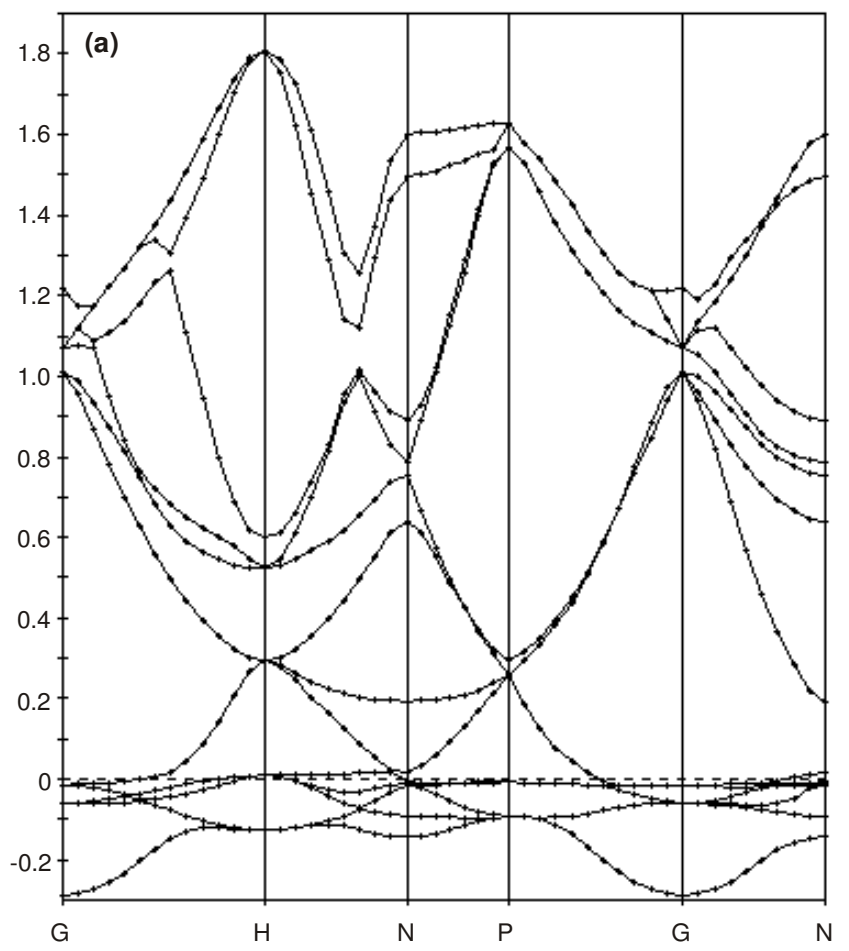

Energy (Ha)

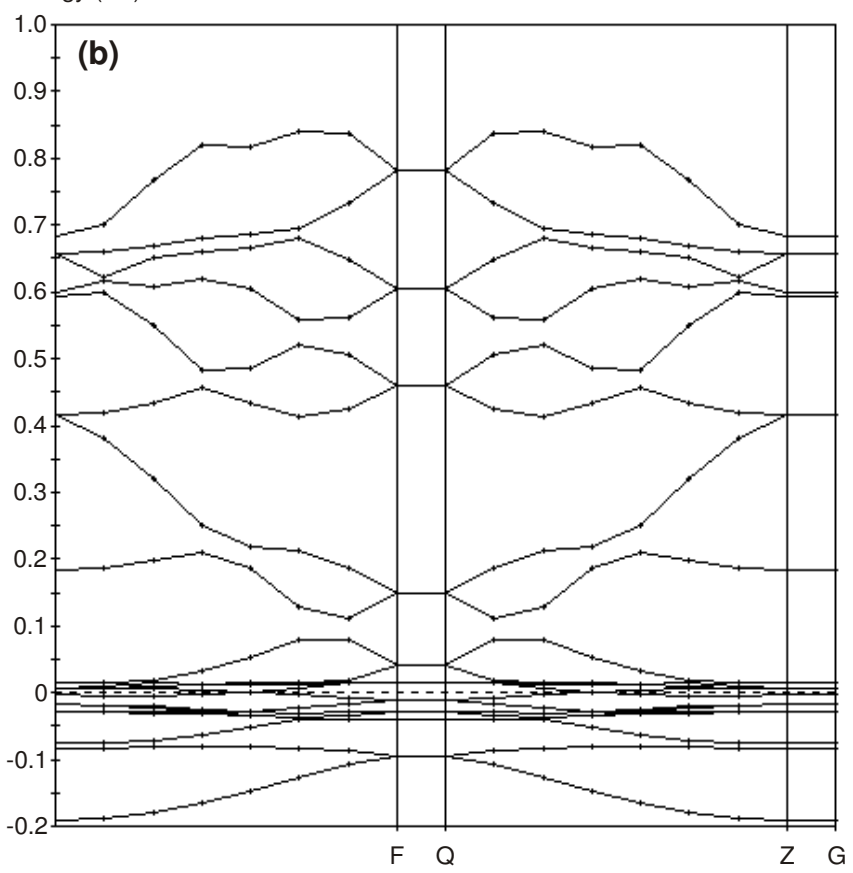

Fig. 3. Construction of energy band of $\mathrm{Fe}$ bulk (a) and $\mathrm{Fe}(001)$ (b). Transformation of Fe from a bulk (3D system, symmetry group IM-3M) to $\mathrm{Fe}(001)$ (2D system, symmetry group P4/NMM) changes energy band (Fig. 3), however, conductivity of iron is hardly changed. This is proved by the absence of band gap in both cases forming a stable barrier to protect Fe surface from oxidative species $^{9,22,23}, \mathrm{H}^{+}$. From our point of view, however, there is no study that considers nature of bonds between pyridine and surface iron atoms. As our results mentioned above, when pyridine molecules are adsorbed on $\mathrm{Fe}(001)$ surface, orientation of $\mathrm{N} \cdots \mathrm{Fe}$ is priority. Calculation results of charges on atoms in pyridine molecule are given in Table-3, in which, pyridines adsorbed on pure $\mathrm{Fe}$, impure $\mathrm{Fe}$ containing $\mathrm{C}$ or $\mathrm{O}$ are denoted as $\mathrm{Py}-\mathrm{Fe}, \mathrm{Py}-\mathrm{Fe}(\mathrm{C})$ and $\mathrm{Py}-\mathrm{Fe}(\mathrm{O})$, respectively.

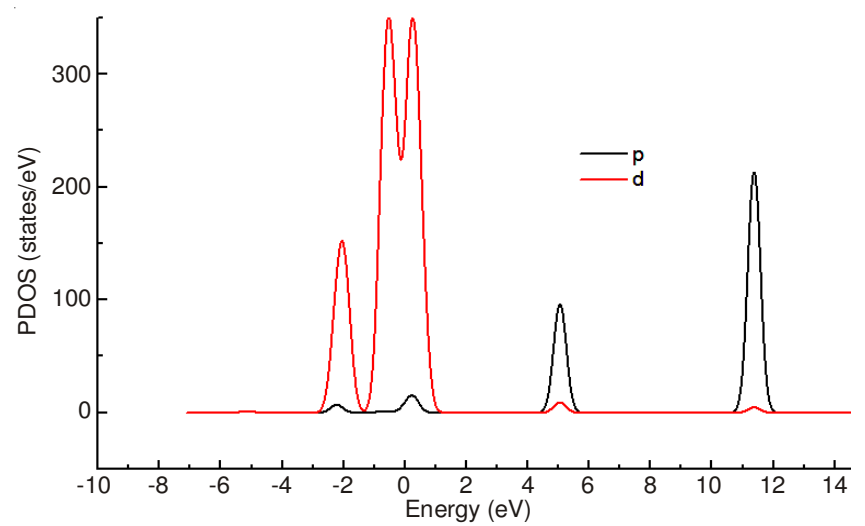

Fig. 4. Partial density of states of $p$ and $d$ states for $\mathrm{Fe}$ atoms in $\mathrm{Fe}(001)$

Table-3 reveals that the interaction between surface Fe atoms and pyridine molecules occurs vigorously in aqueous media of water. This strong interaction is proved by negative value of adsorbed energies corresponding to chemical adsorption $^{24}$.

Analysis result (Fig. 5) indicates that there is a change in electron structures of iron surface when pyridine molecules were adsorbed. This change only occurs when there is a chemical change and confirms the existence of chemical interaction between $\mathrm{Fe}$ and $\mathrm{N}$ of pyridine molecule. On the other hand, when pyridine molecules are adsorbed on surface of iron, states of unoccupied d of iron, located over Fermi level, appear with higher state density value corresponding to a decrease of d electron density of iron due to the conservation of states. This is a shift of electron from $d$ orbital of Fe to $\mathrm{N}$ atom [and $\mathrm{O}$ atom on $\mathrm{Py}-\mathrm{Fe}(\mathrm{O})$ system].

When electron density on d orbital of Fe decreases, the removal of the next electron becomes much more difficult, namely, ionization energy of Py-Fe systems where pyridine molecules are adsorbed is larger than that of Fe systems where no pyridine molecule is adsorbed. The difference in ionization energy of Fe and Py-Fe systems is also proved by calculation result in Table-4.

Ionization energies of systems were calculated as follows: $\mathrm{Fe}(\mathrm{X})(\mathrm{X}=\mathrm{C}, \mathrm{O}$ impure system $)-\mathrm{e} \rightarrow \mathrm{Fe}^{+}, \Delta \mathrm{E}_{1}=\mathrm{I}$ 
TABLE-4

IONIZATION ENERGY $\left(\mathrm{kJ} \mathrm{mol}^{-1}\right)$ OF DIFFERENT SYSTEMS: PYRIDINE, $\mathrm{Fe}, \mathrm{Fe}(\mathrm{C}), \mathrm{Fe}(\mathrm{O}), \mathrm{Py}-\mathrm{Fe}, \mathrm{Py}-\mathrm{Fe}(\mathrm{C})$

AND Py-Fe(O). THE PRESENCE OF WATER MOLECULES WAS INVOLVED IN ALL CALCULATIONS

\begin{tabular}{cccccccc}
\hline & Pyridine & $\mathrm{Fe}$ & $\mathrm{Fe}(\mathrm{C})$ & $\mathrm{Fe}(\mathrm{O})$ & $\mathrm{Py}-\mathrm{Fe}$ & $\mathrm{Py}-\mathrm{Fe}(\mathrm{C})$ & $\mathrm{Py}-\mathrm{Fe}(\mathrm{O})$ \\
\hline $\mathrm{I}$ & 475.491 & 335.289 & 335.208 & 334.977 & 349.524 & 350.496 & 350.086 \\
\hline
\end{tabular}

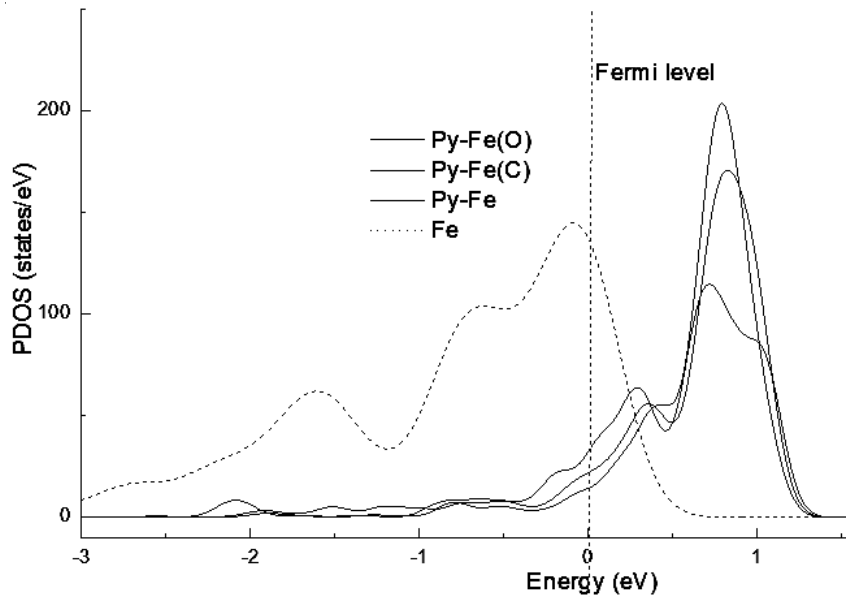

Fig. 5. Partial density of states of $d$ states for $\mathrm{Fe}$ bound to $\mathrm{N}$ in $\mathrm{Fe}, \mathrm{Py}-\mathrm{Fe}$, $\mathrm{Py}-\mathrm{Fe}(\mathrm{C})$ and $\mathrm{Py}-\mathrm{Fe}(\mathrm{O})$

$$
\mathrm{H}^{+}+\mathrm{e} \rightarrow \mathrm{H}, \Delta \mathrm{E}_{2}=0
$$

From (1) and (2) we have:

$\mathrm{Fe}(\mathrm{X})(\mathrm{X}=\mathrm{C}, \mathrm{O}$ impure system $)+\mathrm{H}^{+} \rightarrow[\mathrm{Fe}(\mathrm{X})]^{+}+\mathrm{H}, \Delta \mathrm{E}=\mathrm{I}$

The calculated values of ionization of $\mathrm{Py}-\mathrm{Fe}$ systems are relatively higher than those of Fe systems $\left(\approx 15 \mathrm{~kJ} \mathrm{~mol}^{-1}\right)$ with the molecular ratio of adsorbed pyridine molecule to $\mathrm{Fe}$ atoms is $1: 36$. This difference indicates that the reactivity of $\mathrm{H}^{+}$with $\mathrm{Py}-\mathrm{Fe}$ systems is much lower than the reactivity of $\mathrm{H}^{+}$with $\mathrm{Fe}$ systems. Especially, for impure Fe system (Fe contains impurity of $\mathrm{C}$ or $\mathrm{O}$ atoms), adsorption of pyridine molecules on Fe surface becomes easier. This is proved by a larger negative value of adsorption energies and a shortening of N...Fe bond from 2.054 $\AA$ for Py-Fe to $2.014 \AA$ for $\mathrm{Py}-\mathrm{Fe}(\mathrm{C})$ and to $1.993 \AA$ for $\mathrm{Py}-\mathrm{Fe}(\mathrm{O})$. This result has an importantly practical significance as iron materials is always impure iron containing some other elements such as $\mathrm{C}$ or $\mathrm{O}$ or S...etc. Therefore, pyridine indeed exhibits good corrosion inhibition for steel.

In generation, interactions between $\mathrm{N}$ of pyridine molecules and $\mathrm{H}^{+}$depend on the negative charge on $\mathrm{N}$ atom. For $\mathrm{N}$ atom, which has a lager negative charge, its interaction with $\mathrm{H}^{+}$is easier. This reduces the attack of $\mathrm{H}^{+}$on Fe surface. When pyridine molecules are adsorbed, negative charges on $\mathrm{C}$ and $\mathrm{N}$ atom increase. The negative charge on $\mathrm{N}$ atom increases gradually from $\mathrm{Py}-\mathrm{Fe}$ to $\mathrm{Py}-\mathrm{Fe}(\mathrm{O})$ system and reaches the highest value at $\mathrm{Py}-\mathrm{Fe}(\mathrm{C})$ system (Table-4). As electronegativity of $\mathrm{O}$ atom is much higher than that of $\mathrm{C}$ atom, therefore electrons are attracted to $\mathrm{O}$ atom site leading to lower negative charge on $\mathrm{N}$ atom of $\mathrm{Py}-\mathrm{Fe}(\mathrm{O})$ system in comparison to negative charge on $\mathrm{N}$ atom of $\mathrm{Py}-\mathrm{Fe}(\mathrm{C})$ system.

Overall, mechanism of corrosion inhibition of pyridine on Fe can be said that pyridine molecules interact vigorously with surface Fe to form a stably protective layer and a system with higher ionization in comparison to original system due to a decrease in electron density on d orbital of Fe. The electron shift from iron to pyridine molecules causes a significant increase in negative charge on $\mathrm{N}$ atom. This leads to the fact that $\mathrm{H}^{+}$species interacts with $\mathrm{N}$ atom of adsorbed pyridine molecules more vigorously instead of reacting with Fe atoms.

\section{Conclusion}

In this study, theoretical model closed to real system was employed with periodic boundary conditions and effects of solvent molecules. Therefore, obtained results could be good for practical work. Mechanism of corrosion inhibition of pyridine on different Fe systems was interpreted. Our study proved that pyridine prevents corrosion better for impure iron.

\section{ACKNOWLEDGEMENTS}

The authors acknowledged the financial support from Ministry of Education and Training through B2010-17-240 project.

\section{REFERENCES}

1. E. Jamalzadeh, A.H. Jafari and S.M.A. Hosseini, J. Mol. Struct. (Theochem), 870, 23 (2008).

2. A. Attayibat, R. Touzani, S. Radi, S. El-Kadiri, S. Sari, I. Abdelli and S. Ghalem, Asian J. Chem., 21, 105 (2009).

3. F. Bentiss, M. Traisnel and M. Lagrenee, Corros. Sci., 42, 127 (2000).

4. I. Sheikhshoaie, F. Baghaei and A. Dadgarnezhad, Asian J. Chem., 18, 1903 (2006).

5. V.S. Sastri, Corrosion Inhibitors: Principles and Applications, 1st ed. Willey, New York, p. 43 (1998).

6. K.F. Khaled, Electrochim. Acta, 48, 2493 (2003).

7. M. Bouayed, H. Rabaa, A. Srhiri, J.Y. Saillard, A.B. Bachirnand and A. Le Beuze, Corros. Sci., 41, 501 (1999).

8. C. Ögretir, D. Özögüt, S. yarligan and T. Arslan, J. Mol. Struct. (Theochem.), 759, 73 (2006).

9. Ü. Ergun, D. Yüzer and K.C. Emregül, Mater. Chem. Phys., 109, 492 (2008).

10. M. Lashkari and M.R. Arshadi, Mater. Chem. Phys., 299, 131 (2004).

11. M. Lashkari and M.R. Arshadi, Mater. Chem. Phys., 299, 131 (2004).

12. B. Delley, Mol. Simul., 32, 117 (2006).

13. J.P. Perdew and Y. Wang, Phys. Rev. B, 45, 13244 (1992).

14. D.R. Hamann, M. Schluter and C. Chiang, Phys. Rev. Lett., 43, 1494 (1979).

15. H.J. Monkhorst and J.D. Pack, Phys. Rev. B, 13, 5188 (1976).

16. A.Y. Li and S.W. Wang, J. Mol. Struct. (Theochem.), 807, 191 (2007).

17. G. Herzberg, Electronic Spectra and Electronic Structure of Polyatomic Molecules, Van Nostrand, New York (1966).

18. L. Zwell, D.E. Carnahan and G.R. Speich, Metall. Mater. Trans. B, 1, 1007 (1970).

19. R.G. Parr and W. Yang, J. Am. Chem. Soc., 106, 4049 (1984).

20. R.G. Parr and W. Yang, Density Functional Theory of Atoms and Molecules, Oxford University Press, New York (1989).

21. P. Geerlings, F. De Proft and W. Langenaeker, Chem. Rev., 103, 1793 (2003).

22. B. Sanyal, Prog. Org. Coat., 9, 165 (1981).

23. S.A. Abd El-Maksoud and A.S. Fouda, Mater. Chem. Phys., 93, 84 (2005).

24. P. Atkins and J. de Paula, Physical Chemistry, New York, edn. 7 (2002). 